\title{
Abordagem do Tema Socioambiental "Lixo em Meio Aquático": Uma Estratégia Reflexiva Com Enfoque CTS no Ensino de Química
}

\author{
João Bosco Paulain Santana Júnior*, Sidilene Aquino de Farias ${ }^{* *}$
}

\section{Resumo}

Este estudo teve por finalidade analisar as contribuições do tema socioambiental "Lixo em Meio Aquático" para promover a reflexão e o posicionamento de estudantes do Ensino Médio frente às relações ciência, tecnologia e sociedade no mundo contemporâneo. Para tanto, adotamos a pesquisa qualitativa, que direciona para a compreensão dos fenômenos que ocorrem em situações de aprendizagem. A pesquisa contou com a participação de 18 alunos dos três níveis do Ensino Médio de uma escola pública. Os dados foram coletados mediante o desenvolvimento de um curso temático, por meio de produções textuais e discursos registrados em relação à participação dos estudantes durante as atividades. Esses dados foram tratados de acordo com os pressupostos da Análise Textual Discursiva e estruturados a partir de subtemas abordados no curso. Os resultados obtidos indicam que a proposta contribuiu para que os estudantes conseguissem estabelecer relações entre os saberes cotidianos e químicos a partir do tema trabalhado. Nesse sentido, a estratégia favoreceu a conscientização e reeducação socioambiental dos participantes da pesquisa.

Palavras-chave: Ensino de Química; Temas Socioambientais; Lixo em Meio Aquático.

* Doutorando em Química, com foco em Ensino de Química, pelo Programa de Pós-Graduação em Química, da Universidade Federal do Amazonas (PPGQ/UFAM). Professor Mestre, do Ensino Médio na rede Estadual de Educação do Amazonas, na cidade de Manaus, Brasil. E-mail: junior.paullain@gmail.com

* Doutora em Ciências, com foco em Química, pela Universidade Federal de São Carlos (UFSCar). Professora Doutora, do Curso de Licenciatura em Química e do Programa de Pós-graduação em Química da Universidade Federal do Amazonas (PPGQ/UFAM), Manaus/AM, Brasil. E-mail: sfarias@ufam.edu.br

Recebido em: 10/07/2020; Aceito em: 31/08/2021

https://doi.org/10.5335/rbecm.v4i2.11302

http://creativecommons.org/licenses/by-nc-nd/4.0

ISSN: 2595-7376 


\section{Introdução}

No cenário atual, torna-se fundamental o desenvolvimento de estratégias educacionais que contribuam para a promoção de cidadãos reflexivos, críticos e que saibam se posicionar frente às questões que permeiam a sociedade. Nesse contexto, a Química se apresenta como uma área de conhecimento escolar capaz de contribuir para o desenvolvimento do olhar científico, favorecendo a compreensão dos educandos sobre fenômenos que ocorrem no mundo e possibilitando a aquisição de saberes e habilidades que auxiliam na tomada de decisões capazes de minimizar problemas relacionados aos contextos nos quais esses indivíduos se encontram (SILVA, et al., 2008; XAVIER; SOLEDADE, 2013; ZANOTTO; SILVEIRA, SAUER, 2016).

Para tanto, torna-se necessário que nos contextos educacionais haja o rompimento com o uso excessivo das estratégias tradicionais de ensino, visto que essas propostas não dão conta de formar indivíduos na sua integralidade. Isso ocorre, pois, essas estratégias voltam-se para o ensino de conceitos, memorização e a promoção de um aluno passivo em sala de aula (ZABALA, 2010; DOMICIANO, LORENZETTI, 2020). Além disso, desprezam as relações entre a Química, o cotidiano e a realidade dos estudantes, e tratam o conhecimento químico como algo estático e fragmentado (CARVALHO; GIL-PÉREZ, 2006; DINIZ, et al., 2021).

Essas limitações da abordagem tradicional impactam diretamente na qualidade do processo de ensino e aprendizagem, pois desconsideram as estruturas dos sujeitos, seus sentimentos, emoções e particularidades na forma de pensar e agir (SHULMAN, 1986). Isso ocorre porque a abordagem tradicional está pautada no ensino de transmissão, difundindo a instrução e transmitindo os conhecimentos por meio da exposição dos conteúdos, tornando o processo educativo em um jogo simplório de palavras e escondendo o seu poder transformador na vida de um professor e seus alunos. Freire (2016), classifica esse tipo de abordagem como educação bancária, na qual, o estudante aparece simplesmente como uma espécie de depósito de conteúdo. Desse modo, a ação do professor ocorre independentemente dos interesses dos alunos, não havendo relação entre os conteúdos e propostas metodológicas com o cotidiano e realidades sociais dos estudantes (SANTOS, 2005; ZABALA, 2010).

Sobre isso, Freire (2016, p. 118) afirma que a verdadeira educação libertadora "[...] não pode ser a do depósito de conteúdo, mas a da problematização dos homens em suas relações com o mundo", de modo que esse conhecimento transforme o apren- 
diz e ele seja capaz de atuar nos cenários em que se desenvolve. Portanto, torna-se necessário a utilização de outras dinâmicas, caminhos e estratégias para que o conhecimento seja construído, de modo que as abordagens tradicionais dialoguem com aquelas denominadas "inovadoras". Nesse sentido, Neves et al., (2019, p. 41) declaram que enquanto "[...] numa face da moeda se tem uma tarefa de apresentar os conteúdos de maneira completa, profunda e detalhada, na outra temos a força e a responsabilidade de transformar alunos [...]" em pessoas capazes de analisar problemas complexos, trabalhar em equipe, ter pensamento criativo, promovendo a motivação para que o aluno continue buscando o aprendizado e o desenvolvimento intelectual.

Dessa maneira, o processo de ensino e aprendizagem deve envolver uma ação mais direta daquele que aprende, havendo espaço para questionamentos e experiências. De acordo com Bacich e Moran (2018), as pesquisas no campo da neurociência revelam a necessidade de substituir cada vez mais as estratégias que tornam os alunos passivos - aqueles que apenas ouvem, anotam e mostram o quanto aprenderam -, por ações que os tornem mais ativos, de maneira que o professor fale menos, oriente mais e o aluno participe ativamente através das suas ações e discursos, resultando em uma aprendizagem mais reflexiva, significativa e prazerosa ao indivíduo.

Isto posto, percebe-se a importância da implementação de estratégias que integrem o mundo da vida com o mundo da escola, derrubando barreiras que isolem os conhecimentos científicos e os saberes cotidianos e evitando a percepção da Ciência como um fragmento que não se relaciona com as questões do mundo, mas sim como um saber que colabora para a leitura de fenômenos e compreensão do mundo vivido (COSTA-BEBER; RITTER; MALDANER, 2015). No tocante a isso, a contextualização surge como uma alternativa válida e capaz de promover a articulação entre os conhecimentos científicos e os saberes da vida cotidiana, pois consiste na busca por relações entre àquilo que o aluno sabe sobre o contexto em questão e os conteúdos específicos que servirão de base para a explicação desse contexto (FIDELIS; GIBIN, 2016).

Consequentemente, a contextualização contribui para facilitar a aprendizagem porque aproxima os conteúdos científicos da vida cotidiana, propiciando significado e sentido àquele que aprende (COSTA-BEBER; RITTER; MALDANER, 2015). Além disso, essa abordagem desenvolve habilidades de análise, interpretação e avaliação, 
que, consequentemente, levam a tomada de decisões (FIDELIS; GIBIN, 2016). Sendo assim, o conhecimento escolar se caracteriza como contextualizado no momento que possibilita a constituição de sujeitos hábeis para decidir conscientemente em contextos previamente concebidos (COSTA; LOPES, 2018).

No ensino de Química, a abordagem contextualizada amplia os conhecimentos e leva os aprendizes a uma dimensão social, ambiental e tecnológica capaz de ajudá-los a encontrar sentido e significado naquilo aprendem (BUFFOLO; RODRIGUES, 2015; ZANOTTO; SILVEIRA; SAUER, 2016). E uma forma de realizar essa contextualização, é através da abordagem Ciência-Tecnologia-Sociedade (CTS) que surgiu como resultado de movimentos que emergiram após a Segunda Guerra Mundial, a partir do agravamento dos problemas ambientais e das discussões sobre o conhecimento científico e seu papel na sociedade (SANTOS, 2007; DOMICIANO; LORENZETTI, 2020).

O ensino pautado na abordagem CTS tem por finalidade promover a educação científica, tecnológica e ambiental aos cidadãos, contribuindo para o exercício de competências e habilidades necessárias para a tomada de decisões (SANTOS, 2007; DOMICIANO; LORENZETTI, 2020). Além disso, essa abordagem engloba outros aspectos da sociedade, de natureza política, cultural, econômica e histórica, transcendendo a citação dos fenômenos científicos estudados e a exemplificação de situações cotidianas. Ela consiste na integração entre questões cotidianas e o conhecimento científico de forma sistemática, alcançando a concretização dos conteúdos curriculares e auxiliando na significação dos saberes trabalhados (SANTOS, 2007; WATANABE; RODRÍGUEZ-MARÍN, 2018). A abordagem CTS também propõe situações-problemas cotidianos, apresenta conhecimentos que ajudam a entendê-las e alternativas para solucioná-las, favorecendo a contextualização dos conteúdos químicos (FIDELIS; GIBIN, 2016; CHIARO; AQUINO, 2017).

Nessa proposta, os temas socioambientais aparecem como constituintes da abordagem CTS, promovendo discussões abertas e complexas que aproximam os estudantes das suas realidades, auxiliando os educandos a desenvolverem habilidades relacionadas à tomada de decisões sobre questões nas quais estão submergidos e contribuindo para o desenvolvimento de ambientes educacionais mais prazerosos (SANTOS; MORTIMER, 2002; WATANABE; RODRÍGUEZ-MARÍN, 2018). A esse respeito, Carvalho e Watanabe (2019) destacam que o ser humano é parte integrante 
do ambiente e deve refletir e se conscientizar sobre as atitudes, valores e ações que preservem as relações socioambientais.

No tocante a isso, os Parâmetros Curriculares Nacionais (PCN) destacam a importância do trabalho com temas ambientais, a fim de que a escola seja um lugar que cumpra sua função social e promova valores gerais e unificadores a respeito dessas questões (BRASIL, 1997). Por sua vez, as Orientações Educacionais Complementares aos Parâmetros Curriculares Nacionais (PCN+) para o Ensino Médio apresentam a importância da contextualização no Ensino de Ciências, tratando dos impactos ambientais, financeiros e sociais relacionados à produção de energia (BRASIL, 2002). E atualmente, temos a Base Nacional Comum Curricular (BNCC) de 2018, que enfatiza a importância dos aspectos socioambientais, orientando à conscientização, preservação, sustentabilidade e desenvolvimento de habilidades que tornem os indivíduos capazes de rever processos, práticas e implicações das ações humanas sobre as relações socioambientais.

O estudo dessas relações tem o potencial de despertar um maior interesse dos estudantes pelo conhecimento científico, pois contribui para a percepção de sentido e significado do conteúdo estudado(BUFFOLO; RODRIGUES, 2015). Em relação a isso, Latini e Sousa (2011) destacam que os temas relacionados ao meio ambiente devem ser integrados ao currículo escolar e trabalhados de forma interdisciplinar, provocando “[...] mudanças almejadas, atentando para as modificações ambientais causadas pelas ações antrópicas ou naturais, além do uso e implicações ambientais, sociais e econômicas decorrentes dos processos de produção" (p. 144).

Nessa perspectiva, Watanabe e Rodríguez-Marín (2018) e Brito, Siveres e Cunha (2019) elencam atributos que torna complexo e desafiador o trabalho com os temas socioambientais. Dentre esses, podemos citar a “[...] perspectiva de mundo na qual as relações no e entre os sistemas estão claramente evidenciadas, a ponto de se tornarem objetos da ciência" (WATANABE; RODRÍGUEZ-MARÍN, 2018, p. 546), a incorporação de uma incerteza capaz de produzir riscos e a integração às situações abertas e dinâmicas, tornando as questões socioambientais como potencializadoras de uma visão mais complexa. Portanto, trabalhar esse tema não implica necessariamente seguir um fio condutor que levará a resultados definidos, mas abrir possibilidades para que situações não planejadas ocorram, enriqueçam o processo educativo e impliquem em uma mudança de postura sobre àqueles que 
adquirem uma consciência ambiental (WATANABE; RODRÍGUEZ-MARÍN, 2018; COSTA; PONTAROLO, 2019).

Carvalho e Watanabe (2019) consideram que o processo de ensino e aprendizagem deveria proporcionar uma formação capaz de incorporar debates vinculados às questões socioambientais pautando-se basicamente em três pressupostos: criticidade, complexidade e reflexibilidade. A ideia de criticidade consiste num ensino que mobilize um pensamento transformador, buscando um posicionamento crítico dos indivíduos e com propósitos de difusão do conhecimento, problematização, responsabilidade e conscientização socioambiental. Em relação à complexidade, a proposta deve buscar construir uma visão mais dinâmica do mundo, levando a pessoa a interagir e atuar na sociedade contemporânea. A esse respeito, é essencial que a construção do conhecimento científico esteja vinculada às questões sociais, culturais, políticas e econômicas, possibilitando o tratamento de situações-problemas, como a ação do homem sobre a natureza. Por fim, o modelo reflexivo está atrelado às incertezas presentes nos discursos que apontam para os problemas socioambientais, visto que são complexos e nem todos os problemas dessa natureza estão explícitos (WATANABE; RODRÍGUEZ-MARÍN, 2018; CARVALHO; WATANABE, 2019).

Relacionados a isso, numerosas crises vêm afetando as relações socioambientais no planeta. Hernández e Martínez (2019) atribuem essas problemáticas às ações do homem sobre $o$ ambiente, mais especificamente a partir de fenômenos como a globalização agroindustrial e a organização social com suas explorações, desigualdades, conflitos, guerras por recursos naturais e crises de governança. Consequentemente, tem-se o desencadeamento de uma série de problemas e tensões que comprometem a sustentabilidade ecológica, acarretando desastres climáticos e socionaturais cada vez maiores (HERNÁNDEZ; MARTÍNEZ, 2019).

Na visão de Zanirato e Rotondaro (2016), um dos problemas que mais impactam a vida socioambiental é o consumo excessivo. Segundo eles, o consumismo opera num ciclo em que se cria uma necessidade para, em seguida, oferecer um produto "capaz de resolvê-la". Esse ciclo se repete continuamente nos indivíduos inseridos nessa lógica, que buscam sempre estar "atualizados" e "a frente" em relação à moda, às tecnologias e tendências do mercado. $\mathrm{O}$ resultado é o consumo desenfreado, o aumento em larga escala do desperdício e, consequentemente, a deterioração do ambiente. A respeito disso, compartilhamos do pensamento de Zanirato e Rotondaro (2016, p. 86) de que o consumo excessivo "[...] gera conflitos com o meio ambiente 
pelo uso cada vez mais intenso da matéria-prima, de energia e pela produção de resíduos [...]". Consequentemente, se gasta muito mais do que a capacidade de produção natural e assimilação dos resíduos pelo ambiente.

Sobre esses conflitos socioambientais, podemos destacar a poluição aquática como um dos problemas que mais afetam o mundo. A respeito disso, Oliveira e Molica (2017) destacam que quando se tem um descarte de resíduos superior ao potencial de degradação do ecossistema, as consequências são profundas e negativas. Muito dessa poluição advém de esgotos não tratados e lixos descartados diariamente em seus leitos, acarretando águas tão poluídas que em muitos casos não servem mais para serem tratadas novamente (GRASSI, 2001; OLIVEIRA; MOLICA, 2017). Nesse contexto, destacamos o tema socioambiental "Lixo em Meio Aquático", que está atrelado aos problemas inerentes ao despejo de lixo em corpos aquáticos como rios, mares, oceanos, lagos, igarapés e águas subterrâneas. É um tema que além oportunizar o desenvolvimento de ações contextualizadas de ensino e aprendizagem com enfoque CTS, também possibilita que os conteúdos químicos de diferentes níveis de escolaridade sejam explorados, propiciando a integração entre sujeitos de diferentes níveis de ensino.

Em relação aos ambientes aquáticos, é válido destacar que a preservação da água é primordial para a manutenção da vida, ocupando em média $70 \%$ do corpo humano e entre $95 \%$ a $99 \%$ de seres como as águas-vivas (OLIVEIRA; MOLICA, 2017). No mundo, a água recobre $71 \%$ da superfície do Planeta, da qual, aproximadamente $97,4 \%$ consiste em água salgada e apenas $2,61 \%$ em água doce - sendo que desta última, 3/4 equivalem à água congelada dos polos (BRASIL; RESENDE; ZIM, 2016). No Brasil, a maior quantidade de água doce encontra-se na Amazônia, equivalendo a aproximadamente $80 \%$ de toda a água presente em terras brasileiras (OLIVEIRA; MOLICA, 2017). Entretanto, apesar da importância da água para a dinâmica da vida, questões como a exploração excessiva, aliado à falta de esgotos domésticos, aterros sanitários e o descarte irregular de resíduos sólidos urbanos, são alguns dos fatores que agravam a poluição aquática em contextos brasileiros (BRASIL; RESENDE; ZIM, 2016). E mesmo não sendo um problema atual, vem se agravando com o aumento gradativo de lixo descartado nesses ambientes, o que desencadeia outros problemas, de natureza social, política e econômica, nas mais diversas regiões do planeta (OLIVEIRA; MOLICA, 2017). 
Segundo o Panorama dos Resíduos Sólidos 2018/2019, produzido pela Associação Brasileira das Empresas de Limpeza Pública e Resíduos Especiais (Abrelpe), em 2018 foram gerados no Brasil 79 milhões de toneladas de resíduos, dos quais 92\% foram coletados. Apesar do número significativo de coleta, a Abrelpe destaca que além de restarem $8 \%$ de lixo não coletado (6,3 milhões de toneladas), $40 \%$ do lixo coletado é descarregado em lixões ou aterros que não contam com a estrutura e medidas necessárias que garantam a integridade do meio ambiente e da população. Ainda de acordo com o panorama, essa é uma realidade de cerca de 3.000 dos mais de 5.500 municípios do país. Tratam-se de números preocupantes e que requerem a mobilização da sociedade, uma vez que a qualidade de vida e o meio ambiente são afetados pelo destino incorreto do lixo.

Partindo desses pressupostos, o tema socioambiental "Lixo em Meio Aquático" se apresenta com potencial para promover reflexão e aquisição de valores e atitudes que levam a uma maior preocupação com o meio ambiente. É um tema capaz de desenvolver a criticidade e a tomada de decisões que contribuam para a diminuição do lixo, seja por meio de ações diretas ou através do compartilhamento de informações sobre àquilo que foi aprendido, de maneira que haja uma influência positiva sobre pessoas e comunidades. Além disso, esse assunto permite que o estudo da Química seja articulado com diferentes aspectos da sociedade, sejam eles científicos, políticos, tecnológicos e ambientais.

Do exposto, buscamos responder a seguinte questão de pesquisa: quais as contribuições do tema socioambiental "Lixo em Meio Aquático" na promoção de reflexões e posicionamentos de estudantes do Ensino Médio? O objetivo do estudo foi analisar as contribuições do tema socioambiental "Lixo em Meio Aquático" para promover reflexão, conscientização e criticidade de alunos do Ensino Médio frente às relações CTS no mundo contemporâneo.

\section{Procedimentos Metodológicos}

Esta pesquisa foi desenvolvida com base na abordagem qualitativa, que leva em consideração o contexto em que o sujeito se encontra, levando em conta que o ambiente tem influência sobre as ações e aprendizados dos indivíduos (CRESWELL, 2007). O interesse do pesquisador volta-se mais para os fenômenos que vão ocorrendo nas situações de aprendizagem, ou seja, os significados atribuídos, as perspectivas, 
os discursos, comportamentos e a forma como os educandos encaram as novas situações e informações apresentadas. Sendo assim, os resultados se apresentam como parte das informações que vão sendo obtidas e não como o cerne da pesquisa (CRESWELL, 2007).

O estudo é fruto de uma pesquisa maior, de mestrado, desenvolvido com 18 alunos do Ensino Médio e provenientes de uma escola da rede pública. A pesquisa atende às exigências do Comitê de Ética em Pesquisa, sob o parecer de número 1.992.781, que avalia pesquisas científicas envolvendo seres humanos conforme a resolução 466/12 do Conselho Nacional de Saúde.

Para coletar os dados, elaboramos uma Unidade Didática integrando os conteúdos químicos à temática socioambiental "Lixo em Meio Aquático", que foi desenvolvida por meio de um curso de 40 horas, dividido em 13 encontros, no laboratório de informática, do Departamento de Química, da Universidade Federal do Amazonas. A escolha do tema se justifica por se apresentar como um assunto próximo da realidade dos estudantes, uma vez que Manaus apresenta problemas graves relacionados ao descarte desenfreado de lixo em meios aquáticos, principalmente dos igarapés que a cortam.

Os dados apresentados neste trabalho foram coletados por meio de debates e produções textuais, com ênfase nos resultados obtidos a partir de fóruns virtuais realizados na plataforma Moodle e discursos provenientes de debates. As aulas em que os fóruns foram realizados estiveram voltados para a discussão dos seguintes subtemas: fontes poluidoras da água; consequências do descarte desenfreado de lixo em água; e conscientização sobre a produção de lixo e possíveis alternativas (Quadro 1).

Nessas aulas, os alunos puderam expressar suas ideias a partir de suas próprias experiências e dos problemas e assuntos apresentados pelo pesquisador. Em relação aos debates, esclarecemos que foram realizados em praticamente todos os encontros do curso, mas daremos ênfase nos discursos provenientes das aulas que abordaram os subtemas citados anteriormente e dos discursos em que os estudantes buscaram fazer relações entre o tema norteador e a Química. No Quadro 1 é apresentado uma síntese dos conteúdos trabalhados nessas aulas a partir de três vertentes: aspectos gerais, aspectos históricos, econômicos, ambientais e sociais e os aspectos conceituais de Química. 
Quadro 1: Síntese dos conteúdos abordados nas aulas.

\begin{tabular}{|c|c|c|}
\hline \multicolumn{3}{|c|}{ Lixo em Meio Aquático } \\
\hline Aspectos Gerais & $\begin{array}{l}\text { Aspectos Históricos, Econômicos, } \\
\text { Ambientais e Sociais }\end{array}$ & Aspectos Conceituais \\
\hline $\begin{array}{l}\text { - Água. } \\
\text { - Lixo. } \\
\text { - Relações cotidianas. } \\
\text { - Vida e meio ambiente. }\end{array}$ & $\begin{array}{l}\text { - Aumento do consumismo e lixo. } \\
\text { - Fontes geradoras de poluentes } \\
\text { aquáticos. } \\
\text { - Conscientização e impactos do } \\
\text { descarte de lixo. } \\
\text { - Alternativas para o lixo. }\end{array}$ & $\begin{array}{l}\text { - Substâncias químicas. } \\
\text { - Fórmulas e equações químicas. } \\
\text { - Propriedades e representação } \\
\text { dos metais. } \\
\text { - Unidades de medida. } \\
\text { - Acidez e basicidade. }\end{array}$ \\
\hline
\end{tabular}

Os dados obtidos a partir das produções textuais feitas pelos estudantes foram analisados com base nos pressupostos da Análise Textual Discursiva (ATD). Trata-se de um método que tem por finalidade auxiliar na compreensão dos fenômenos que estão sendo vivenciados e investigados. A ATD auxilia o pesquisador na organização e busca por significados inerentes aos resultados obtidos. Essa técnica apresenta quatro etapas gerais: unitarização dos dados, categorização das informações presentes nas unidades estabelecidas, busca por significados nas categorias e reestruturação sistemática dos dados (MORAES, 2003; GALIAZZI; SOUSA, 2019).

Partindo desses pressupostos, a análise das produções textuais nos fóruns possibilitou a criação de quatro categorias: efeitos do consumismo; problemas oriundos do descarte desenfreado de lixo em meio aquático; atitudes e alternativas para minimizar os problemas do lixo em meio aquático; e, relações entre a Química, lixo e efluentes (Quadro 2). Destacamos que o curso teve um viés tecnológico, o que explica a presença de instrumentos tecnológicos na proposição das atividades.

Quadro 2: Principais atividades das aulas abordadas.

\begin{tabular}{|l|l|}
\hline \multicolumn{1}{|c|}{ Categorias } & \multicolumn{1}{c|}{ Atividades } \\
\hline Efeitos do consumismo & $\begin{array}{l}\text { Apresentação do vídeo "a história das coisas", debate e conclusão } \\
\text { por parte do pesquisador. }\end{array}$ \\
\hline $\begin{array}{l}\text { Problemas oriundos do des- } \\
\text { carte desenfreado de lixo } \\
\text { em meio aquático }\end{array}$ & $\begin{array}{l}\text { Apresentação do vídeo "rio mais poluído do mundo - Citarum/Indo- } \\
\text { nésia", debate, aula dialogada e participação em fórum na Plataforma } \\
\text { Moodle. }\end{array}$ \\
\hline $\begin{array}{l}\text { Atitudes e alternativas para } \\
\text { minimizar os problemas do } \\
\text { lixo em meio aquático }\end{array}$ & $\begin{array}{l}\text { Atividade de pesquisa nos igarapés de Manaus com gravação e pos- } \\
\text { terior apresentação de vídeo por parte dos estudantes, apontamentos } \\
\text { do pesquisador e discussão final. }\end{array}$ \\
\hline $\begin{array}{l}\text { Relações entre a Química, } \\
\text { lixo e efluentes }\end{array}$ & $\begin{array}{l}\text { Apresentação de animações e simuladores, aulas dialogadas com } \\
\text { utilização de imagens e esquemas no Power Point, discussões e ex- } \\
\text { perimentação. }\end{array}$ \\
\hline
\end{tabular}


Destacamos ainda, que na apresentação dos discursos e textos construídos pelos participantes, esses trechos foram codificados em E1 = Estudante 1, E2 = Estudante 2 , e assim, sucessivamente.

\section{Resultados e Discussão}

Os resultados foram organizados a partir das categorias estabelecidas durante a análise, de modo que sistematizamos as reflexões e posicionamentos dos estudantes enfatizando a potencialidade do ensino da Química por meio de temas socioambientais.

\section{Efeitos do consumismo}

Na perspectiva dos estudantes, o consumismo traz efeitos nocivos ao meio ambiente e a sociedade, sendo esta última classificada por eles como consumista. A respeito disso, apresentamos a seguir (Quadro 3) as subcategorias e unidades dessa análise.

Quadro 3: Efeitos do consumismo nas concepções dos estudantes.

\begin{tabular}{|l|l|}
\hline \multicolumn{1}{|c|}{ Subcategorias } & \multicolumn{1}{c|}{ Unidades Representativas } \\
\hline Danos ambientais & $\begin{array}{l}\text { O elevado consumo contribui para o acúmulo de lixo, que é diretamente levado } \\
\text { para um local onde é enterrado ou incinerado, isso causa poluição (E11). }\end{array}$ \\
\hline $\begin{array}{l}\text { Sociedade do } \\
\text { Consumo }\end{array}$ & $\begin{array}{l}\text { A sociedade vive num ciclo consumista gastando cada vez mais, respirando ar } \\
\text { poluído, adquirindo doenças e sendo manipulada (E7). }\end{array}$ \\
\hline Problemas urbanos & Lixos em montinho jogados em esquina de ruas (E14). \\
\hline
\end{tabular}

Os participantes identificaram o consumismo como um forte promotor da geração de lixo. Os discursos observados e apresentados no Quadro 3 sugerem que eles reconheceram algumas das consequências do consumo excessivo e o quanto esse sistema pode ser danoso ao ambiente e sociedade, visto que potencializa o desperdício e a produção de rejeitos (ZANIRATO; ROTONDARO, 2016). Essas questões foram debatidas nas aulas e instigaram os educandos a expressarem seus entendimentos e preocupações, enfatizando pontos de vista inerentes às suas próprias experiências, como pode ser visto no discurso do participante E14 quando destaca "lixos 
em montinho" - problema comum na cidade de Manaus e que causa mal cheiro e a propagação de doenças. Na visão deles, o consumismo acaba contribuindo para esse tipo de situação como resultado do aumento do descarte de lixo em áreas urbanas.

Além disso, eles enfatizaram consequências mais gerais do efeito consumista como "ar poluído" (E7) resultante dos processos industriais de produção, além da propagação de "doenças" (E7) e "acúmulo de lixo" (E11) oriundos da poluição. Essas concepções fornecem indícios de que eles estabeleceram possíveis relações entre os problemas ambientais estudados e o domínio social. Também se percebe que o processo de ensino e aprendizagem contextualizado a partir de um tema socioambiental pode ter favorecido a capacidade de julgamento, crítica e posicionamento frente ao assunto abordado no curso.

Diante desses pressupostos, destacamos que o ensino exclusivamente tradicional e voltado para a simples citação de fenômenos científicos ou meros exemplos do cotidiano não seria capaz de gerar tais reflexões porque os alunos não teriam informações suficientes para fazer relações e inferências cotidianas, visto que as práticas tradicionais não se preocupam com as relações entre o conhecimento científico e a sociedade, mas voltam-se para a memorização de conceitos (ZABALA, 2010; DOMICIANO; LORENZETTI, 2020). Por sua vez, um ensino pautado na abordagem CTS valoriza os saberes dos estudantes e os integra aos temas cotidianos e científicos, propondo situações-problemas, gerando conhecimentos que ajudam na compreensão desses problemas e promovendo uma aprendizagem contextualizada e abrangente dos conteúdos químicos (SANTOS, 2007; BUFFOLO; RODRIGUES, 2015).

\section{Problemas oriundos do descarte desenfreado de lixo em meio aquático}

A questão dos "problemas oriundos do descarte desenfreado de lixo em meio aquático" foi um dos tópicos que mais despertou o interesse e a vontade de participar dos estudantes. Eles trouxeram conhecimentos pessoais e suas próprias experiências para o curso, estabelecendo relações entre estes e os assuntos trabalhados nos encontros. Para eles, o descarte excessivo de lixo em ambientes aquáticos pode gerar problemas de desequilíbrios ambientais, qualidade de vida, econômicos, escassez de água e ainda comprometer os recursos hídricos do Amazonas. O Quadro 4 apresenta discursos que exemplificam os posicionamentos dos participantes. 
Quadro 4: Problemas apontados pelos estudantes como resultado do descarte excessivo de lixo em meio aquático.

\begin{tabular}{|c|c|}
\hline Subcategorias & Unidades Representativas \\
\hline $\begin{array}{l}\text { Desequilíbrios am- } \\
\text { bientais }\end{array}$ & Os entupimentos de bairros, enchentes devastadoras, poluição de rios (E7). \\
\hline Qualidade de vida & $\begin{array}{l}\text { As consequências são as piores possíveis. Mal cheiro, poluição, alagamento, } \\
\text { etc. Eu moro atrás de um igarapé e às vezes sofro muito com o mal cheiro (E18). }\end{array}$ \\
\hline $\begin{array}{l}\text { Obstáculo à eco- } \\
\text { nomia }\end{array}$ & Prejudica rios de navegação e transporte [...] Isso atrapalha a pesca (E14). \\
\hline Escassez de água & $\begin{array}{l}\text { Se continuar no ritmo em que estamos daqui uns anos não haverá mais água } \\
\text { potável para se consumir (E6). }\end{array}$ \\
\hline $\begin{array}{l}\text { Comprometimen- } \\
\text { to dos recursos } \\
\text { hídricos }\end{array}$ & $\begin{array}{l}\text { Se a população de Manaus continuar a jogar lixo e as fábricas resíduos, os nos- } \\
\text { sos rios serão os mais poluídos do mundo (E2). }\end{array}$ \\
\hline
\end{tabular}

Os participantes E7 e E18 fizeram relações entre os problemas apresentados e àqueles vivenciados na cidade. O estudante E7, por exemplo, citou um problema comum na cidade, as enchentes dos igarapés provocadas pelas chuvas. Problema este que pode ser atribuído à falta de estrutura e obstruções provocadas pelo lixo descartado nesses ambientes. O estudante E18, por sua vez, relacionou os danos provenientes do descarte de lixo em meio aquático com aqueles que fazem parte da sua própria realidade, citando problemas como o "mal cheiro" presente nessas localidades.

Esses discursos indicam a reflexão promovida pelo estudo do tema socioambiental e a presença das questões cotidianas no processo de ensino e aprendizagem, o que pode desencadear novas atitudes e ações, pois o sujeito percebe que interfere positiva ou negativamente nas relações socioambientais. A respeito disso, Buffolo e Rodrigues (2015) destacam que o ensino pautado em temas socioambientais deve ir além de informações sobre a degradação ambiental, de modo que os saberes trabalhados favoreçam a análise e compreensão das relações entre o ser humano e a natureza.

Entretanto, apesar da educação ter um papel fundamental na construção da igualdade de acesso a oportunidades, na qualidade de vida e formação de uma consciência socioambiental, não é suficiente para promover um desenvolvimento sustentável (BRITO; SIVERES; CUNHA, 2019). Logo, ao considerarmos a complexidade, interdisciplinaridade e o potencial da educação socioambiental, percebemos que tornar esse modelo bem-sucedido requer "[...] autonomia, descentralização, 
diversidade e comunidade [...]" (BRITO; SIVERES; CUNHA, 2019, p. 613), pois ambiente e sociedade estão ligados entre si. Quando a proposta é exitosa, espera-se que os indivíduos compreendam a problemática ambiental, tenham seus comportamentos transformados e influenciem àqueles que estão ao seu redor. Ou seja, busca-se contribuir para a transformação da realidade, fomentando o pensamento crítico, reflexivo e propositivo (COSTA; PONTAROLO, 2019).

Para tanto, deve-se promover uma reestruturação do espaço educacional tradicional em ambientes modernos que priorizam a construção e trocas de conhecimentos, favorecendo a colaboração e formação cidadã, além de um sistema democrático que abra espaço para as diferentes vozes, valorizando seus conhecimentos e reestruturando-os numa perspectiva científica, tecnológica, social e ambiental. No tocante a isso, a reflexão crítica implica na compreensão do sentido explícito e implícito das informações, histórias, debates e oferece condições para que os jovens estabeleçam relações coerentes e críticas a respeito dos fenômenos sociais que ocorrem no mundo (XAVIER; SOLEDADE, 2013).

Por fim, ainda com que relação aos discursos do Quadro 4, o posicionamento do estudante E14, sobre a influência da poluição na economia, e do estudante E6, sobre a escassez de água, indicam diferentes perspectivas sobre o problema do descarte excessivo de lixo em meio aquático, percebendo-se indícios da integração entre os conhecimentos trazidos pelos estudantes e àqueles construídos durante 0 curso como resultado da troca de saberes entre aluno-pesquisador, aluno-aluno e das experiências educativas que foram se concretizando no curso.

\section{Atitudes e alternativas para a minimizar os problemas do lixo em meio aquático}

Para trabalhar ideias relacionadas à minimização do descarte de lixo em ambientes aquáticos buscamos visitar partes dos igarapés de Manaus para a observação e gravação de vídeos com o intuito de identificar alguns dos principais resíduos encontrados nessas localidades. De posse dessas informações, realizamos apresentações e debates sobre possíveis alternativas para o lixo e exibimos a partir de recursos audiovisuais informações que ajudassem a complementar os aprendizados. A respeito disso, percebeu-se que atividades que proporcionaram mais autonomia, liberdade e participação aos estudantes tiveram maior aceitação, engajamento, envolvimento 
e despertaram motivações de qualidade. Para esse tópico estabelecemos 6 subcategorias: (1) conscientização e preservação, (2) criação de leis e ações do governo, (3) fiscalização, (4) limpeza e preservação dos ambientes aquáticos, (5) diminuição, organização e destinação adequada do lixo e (6) respeito às leis ambientais.

Em relação à categoria “conscientização e preservação”, a estudante E6 atribui a responsabilidade das questões ambientais à sociedade como um todo. Segundo ela,

\begin{abstract}
"Muitas vezes nós pouco nos preocupamos com o meio ambiente, não paramos para pensar nas consequências que o descarte irregular pode acarretar para os animais e o meio ambiente. Porém, só reclamar não vai adiantar de nada, a iniciativa tem que partir de cada um de nós, eu acredito que se cada ser humano fizesse sua parte não haveria tanta poluição no mundo, só que as pessoas têm a mente muito fechada e não percebem que no fim os prejudicados são elas mesmas" (E6).
\end{abstract}

Esse posicionamento indica a reflexão e perspectiva da estudante sobre a responsabilidade de todos perante o meio ambiente, se colocando como parte do processo e reconhecendo seu papel na sociedade. Carvalho e Watanabe (2019) colaboram desse ponto de vista, afirmando que o ser humano como parte do ambiente deve refletir e agir frente às questões socioambientais.

Estimular reflexões e críticas construtivas são alguns dos objetivos do ensino pautado na abordagem CTS, onde verificamos que a utilização dessa abordagem pode ter contribuído para a inserção social, tornando-os mais propensos e preparados para analisar o problema e tomar decisões. Num sentido mais específico, percebemos que a apresentação do tema "Lixo em Meio Aquático" e a proposição de atividades que exigiram a participação deles por meio de posicionamentos, argumentação e apresentação de possíveis alternativas para solucionar a questão, foram importantes para gerar reflexão e possibilitar a troca de conhecimentos.

Em relação à importância da argumentação, Chiaro e Aquino (2017) defendem que essa estratégia aparece como uma maneira de ampliar a complexidade do conhecimento, as possibilidades de revisão crítica deste e, consequentemente, a qualidade do raciocínio envolvido. Logo, o exercício da argumentação no processo de ensino e aprendizagem fornece ganhos educacionais significativos, proporcionando oportunidades para que os estudantes refinem suas compreensões sobre determinado assunto, absorvam aquilo que é relevante, façam conexões entre contextos e ampliem o poder explicativo de seus conhecimentos (CHIARO; AQUINO, 2017).

Nessa perspectiva, outros estudantes destacaram que a "criação de leis e ações do governo" são alternativas capazes de minimizar o problema. Essa ideia pode ser 
representada pela resposta da aluna E13, na qual, ela destaca que "[...] o governo da cidade deveria dar mais suporte para os rios serem mais limpos, poderiam fazer um projeto ou algo do tipo para tentar minimizar os lixos nos meios aquáticos" (E13). A respeito desse assunto, defendemos que projetos de educação ambiental sejam promovidos em escolas e comunidades, contribuindo para conscientização da população. Tão importante quanto a educação, é fundamental que as autoridades busquem reestruturar ambientes precários de moradia, propiciando condições sanitárias dignas aos cidadãos.

As demais subcategorias, "fiscalização, limpeza e preservação dos ambientes aquáticos", "diminuição, organização e destinação adequada do lixo" e "respeito às leis ambientais", também aparecem nos posicionamentos dos estudantes como caminhos que podem minimizar o problema. Abaixo, são apresentados alguns recortes que representam essas subcategorias.

Quadro 5: Alternativas capazes de minimizar o problema do descarte de lixo em meios aquáticos.

\begin{tabular}{|l|l|}
\hline \multicolumn{1}{|c|}{ Subcategorias } & \multicolumn{1}{c|}{ Unidades Representativas } \\
\hline Fiscalização & $\begin{array}{l}\text { Fiscalizações rigorosas do governo nas fábricas, onde o despe- } \\
\text { jo de resíduos é maior (E2). }\end{array}$ \\
\hline $\begin{array}{l}\text { Limpeza e preservação dos } \\
\text { ambientes aquáticos }\end{array}$ & Iria tirar lixos, limpar a água (E16). \\
\hline $\begin{array}{l}\text { Diminuição, organização e des- } \\
\text { tinação adequada do lixo }\end{array}$ & $\begin{array}{l}\text { Os 3R's é a forma que eu vi para diminuir o excesso de lixo } \\
\text { (E6). }\end{array}$ \\
\hline Respeito às leis ambientais & $\begin{array}{l}\text { O problema poderia ser diminuído se as indústrias seguissem } \\
\text { as regras e respeitassem as leis ambientais (E7). }\end{array}$ \\
\hline
\end{tabular}

O curso foi dividido generalizadamente no estudo da água e suas propriedades, 0 consumismo e o aumento dos resíduos sólidos, compreensão do que é lixo e poluição da água e alternativas para a minimização do problema do lixo em corpos aquáticos. Portanto, o momento em que os participantes expressaram as ideias descritas no Quadro 5 advêm de um percurso seguido no curso. Essas ideias mostram alguns dos caminhos tomados pelos estudantes em relação às atitudes e alternativas para o lixo, revelando conceitos e concepções que possivelmente foram sendo adquiridos ao longo do curso e revelando a potencialidade do tema para a contextualização do Ensino de Química com estudantes do Ensino Médio.

Os 3R's, citado pelo aluno E6, sugere a conscientização dos participantes em relação as ações de reduzir, reutilizar e reciclar. Tratam-se de alternativas apre- 
sentadas aos alunos durante o curso, cujo propósito seria minimizar o descarte e desperdício dos mais variados tipos de materiais, contribuindo para a preservação da natureza. Uma outra curiosidade relaciona-se com a fala do aluno E16, na qual, ele aponta como alternativa a retirada de lixo dos meios aquáticos. Em Manaus é comum que os órgãos governamentais promovam ações de retiradas de lixo dos igarapés, portanto, o discurso do E16 pode ser proveniente de uma experiência vivenciada pelo próprio estudante. Sobre isso, salientamos que apesar da ação de retirada de lixo dos meios aquáticos ter sua relevância, trata-se de uma estratégia com efeito passageiro, sendo primordial que haja uma conscientização ambiental da população e o foco seja evitar que o lixo chegue aos ambientes aquáticos. Um viés que contribui para a implementação dessa proposta é a difusão do conhecimento e responsabilização social (CARVALHO; WATANABE, 2019).

Por fim, a sexta e última subcategoria está relacionada com a "diminuição do consumo". A participante E8 faz um resgate sobre o problema do consumismo, destacando que "[...] o consumo consciente é importante para o Meio Ambiente" (E8). Seu discurso sugere que ela enxergou na diminuição do consumo uma forma de preservar o meio ambiente e reduzir a produção de lixo, o que pode indicar um amadurecimento da estudante em relação ao assunto. Nesse cenário, sabe-se que as crises socioambientais não resultam de causas naturais, mas das intensas ações do homem sobre a natureza. Dentre essas ações está o consumismo, o que deveria nos fazer repensar um novo sistema de produção e consumo, ou seja, novos paradigmas de desenvolvimento (FREITAS; MARQUES, 2019).

\section{Relaçōes entre a Química, lixo e efluentes}

Um dos principais objetivos do curso foi trabalhar os conteúdos químicos de forma contextualizada numa perspectiva CTS. Nesse percurso, abordamos questões relacionadas as características físicas e químicas da água como acidez e basicidade, as transformações químicas e físicas do lixo, as substâncias químicas presentes no lixo, as fórmulas químicas dessas substâncias, entre outros aspectos conceituais. Apesar disso, salientamos que não tivemos por finalidade avaliar as aprendizagens conceituais, mas instigar os estudantes a refletirem sobre a inserção da Química no tema escolhido. Portanto, o modo como eles enxergaram o papel da Química na questão do lixo em meios aquáticos, o estudo da constituição, propriedades e 
transformações que ocorrem no lixo e os aspectos químicos que mais chamaram a atenção deles no curso foram alguns dos nossos focos de interesse.

Sendo assim, observamos que os discursos analisados para essa categoria destacaram a potencialidade do tema para ajudar os educandos a estabelecer relações entre a Química e o problema do lixo. Como resultado dessa análise foi possível estabelecer 4 subcategorias, conforme apresentado no Quadro 6, que mostram algumas das reflexões dos estudantes a partir do estudo da Química numa perspectiva socioambiental.

Quadro 6: Relações estabelecidas pelos estudantes entre o conhecimento químico, lixo e poluição.

\begin{tabular}{|l|l|}
\hline \multicolumn{1}{|c|}{ Subcategorias } & \multicolumn{1}{c|}{ Unidades Representativas } \\
\hline $\begin{array}{l}\text { Química como promo- } \\
\text { tora de conscientização } \\
\text { e contribuinte na mini- } \\
\text { mização do problema }\end{array}$ & $\begin{array}{l}\text { A química estuda e realiza atividades colaboradoras do meio ambiente } \\
\text { (E2). }\end{array}$ \\
\hline $\begin{array}{l}\text { Descarte de produtos } \\
\text { químicos no meio am- } \\
\text { biente }\end{array}$ & $\begin{array}{l}\text { Eu nunca passei pelo igarapé e falei bem assim: nossa! Esse igarapé tá } \\
\text { cheio de química. Eu nunca parei pra pensar. Eu olhava e falava: nossa, } \\
\text { essa água tá poluída. Mas eu nunca pensei: ah, mano, tem cobre, tem } \\
\text { zinco... eu nunca parei pra pensar (E6). }\end{array}$ \\
\hline $\begin{array}{l}\text { Influência dos produtos } \\
\text { químicos na água }\end{array}$ & A acidez da água poluída, os metais encontrados nas águas (E7). \\
\hline Fenômenos químicos & $\begin{array}{l}\text { As reações químicas usadas no processo de reciclagem, os gases que } \\
\text { são liberados para a atmosfera por meio do lixo, os metais pesados que } \\
\text { são liberados de pilhas e baterias, a temperatura de ebulição para derre- } \\
\text { ter o vidro e o metal, a decomposição desses materiais (E7). }\end{array}$ \\
\hline
\end{tabular}

As capacidades e habilidades de compreensão, integração e argumentação desenvolvidas pelos estudantes foram possíveis, dentre outros fatores, devido ao diálogo crítico e problematizador das experiências inerentes ao estudo do tema. Nesse sentido, o ensino caracterizado por uma abordagem CTS deve ser capaz de promover a compreensão dos fenômenos cotidianos numa perspectiva científica, sendo um viés capaz de atribuir sentido aos conteúdos químicos e suas relações com o mundo da vida (COSTA-BEBER; RITTER; MALDANER, 2015).

O Quadro 6 apresenta argumentos relacionados à participação do conhecimento químico na conscientização e diminuição do problema, conforme apontado pela estudante E2. A estudante E6 opta por destacar a presença de substâncias químicas em meios aquáticos, enfatizando que o curso lhe ajudou a ter uma visão mais específica das espécies presentes nesses corpos, como os metais. A participante E7 destaca 
não apenas a possível presença de metais encontrados nas águas, mas também que a acidez dos corpos aquáticos pode ser influenciada pela poluição. Além disso, ela expressa relações entre as reações químicas, o processo de reciclagem e os gases oriundos da decomposição do lixo e incineração desses materiais. Em relação a essa última ideia, é válido destacar que buscamos abordar saberes relacionadas ao lixão e aterros sanitários, as fontes e tipos de poluição e a inserção de contaminantes nos ambientes aquáticos, sendo assim, essas informações podem ter colaborado para que a participante E7 conseguisse elaborar o seu discurso. Ela ainda cita conceitos como "temperatura de ebulição" no processo de reciclagem do vidro e metal.

Esses dados sugerem que em certo grau os estudantes podem ter desenvolvido uma atitude mais crítica e a capacidade de refletir e se posicionar sobre a inserção da Química no problema estudado. Além disso, revelam a potencialidade do assunto na reeducação ambiental dos participantes, pensando como sujeitos que são integrantes do ambiente e, por isso, possuem responsabilidades e deveres no cuidado com o ambiente. Em relação a isso, a educação pautada na perspectiva CTS deve buscar transformar relações entre sujeito e ambiente em um processo de ação e reflexão, visando também o remodelamento das relações sociais e da sociedade com o ambiente (BUFFOLO; RODRIGUES, 2015).

Por fim, os dados indicam que o curso ajudou os estudantes a construírem novas percepções sobre as questões trabalhadas a partir do tema socioambiental "Lixo em Meio Aquático", agregando esses saberes com conhecimentos científicos, tecnológicos e sociais. Essa articulação contribuiu para o desenvolvimento de cidadãos capazes de se posicionar e propor soluções, contemplando um dos principais objetivos do ensino pautado na abordagem CTS.

\section{Considerações Finais}

Diante da necessidade de uma prática docente dinâmica, que rompa com a visão do tradicionalismo em sala de aula, foi possível identificar indícios de que a proposta socioambiental contribuiu para a promoção de alunos mais conscientes. Além disso, o enriquecimento oriundo das relações entre o tema e os aspectos químicos tornaram as situações de aprendizagem mais abrangentes, onde a Química como área de conhecimento foi capaz de ajudar na compreensão dos fenômenos estudados. Isso mostra a relevância da implementação de metodologias que auxiliem na 
formação integral dos indivíduos, ajudando-os a entender como a Química se aplica nas realidades do mundo e desenvolver habilidades de análise e tomada de decisões construtivas em relação aos problemas enfrentados na sociedade.

A pesquisa também mostra a potencialidade do tema "Lixo em Meio Aquático" para trabalhar os conteúdos químicos de uma forma contextualizada com alunos de diferentes níveis do Ensino Médio. Logo, defendemos que o ensino de Química baseado na abordagem CTS não limita o trabalho sistemático dos conteúdos curriculares, mas otimiza o aprendizado, levando à reflexão, compreensão dos fenômenos que ocorrem no mundo e despertando uma maior motivação para a aprendizagem (SANTOS, 2007). Além disso, também foi possível perceber que os estudantes foram capazes de fazer relações entre o aprendido e o vivido na cidade em questão, o que gerou mais curiosidade e desejo de aprender.

Nessa perspectiva, é importante destacar que a utilização de um tema socioambiental foi capaz de contribuir para a geração de motivações de qualidade. Isso, aliado à valorização das interações sociais, a diversificação dos recursos didáticos, a promoção de metodologias que tornaram os estudantes ativos e a apresentação de novidades surgiram como elementos primordiais para que os participantes tivessem uma atitude positiva durante o curso. Além do mais, características como a busca por novidades e pelo aprendizado, entusiasmo e envolvimento nas atividades propostas, apresentaram-se como algumas das características apresentadas pelos estudantes que corroboram a presença de interesse pela aprendizagem.

Dentre as limitações do trabalho está a falta de profundidade nas aprendizagens conceituais, a avaliação das concepções anteriores dos participantes e como e quais concepções foram sendo construídas e formadas durante o curso. Essas limitações abrem espaço para novas pesquisas que tenham por finalidade avaliar a profundidade e estruturação das aprendizagens durante a abordagem do tema. Por fim, é possível inferir que a contextualização da Química a partir do tema socioambiental "Lixo em Meio Aquático" e o estímulo à participação dos estudantes nas atividades foram fundamentais na promoção de um ensino capaz de formar cidadãos que reflitam e se posicionem sobre assuntos presentes nas suas realidades. 


\section{Approach to the Socio-Environmental Theme "Waste in Aquatic Environment": A Reflective Strategy with a CTS Focus on Chemistry Teaching}

\section{Abstract}

This study aimed to analyze the contributions of the socio-environmental theme "Waste in Aquatic Environment" to promote reflection and the positioning of high school students in relation to science, technology and society in the contemporary world. Therefore, we adopted qualitative research, which directs towards understanding the phenomena that occur in learning situations. The research included the participation of 18 students from the three levels of high school in a public school. Data were collected through the development of a thematic course, through textual productions and speeches recorded in relation to student participation during the activities. These data were treated according to the assumptions of Discursive Textual Analysis and structured from sub-themes covered in the course. The results obtained indicate that the proposal contributed to the students being able to establish relationships between everyday and chemical knowledge based on the theme being worked on. In this sense, the strategy favored awareness and socio-environmental re-education of research participants.

Keywords: Chemistry Teaching; Socio-Environmental Themes; Trash in Aquatic Environment.

\section{Referências}

ASSOCIAÇÃO BRASILEIRA DE EMPRESAS DE LIMPEZA PÚBLICA E RESÍDUOS ESPECIAIS. Os descaminhos do lixo. São Paulo, 2019. Disponível em: <http://abrelpe.org.br/brasil-produz-mais-lixo-mas-nao-avanca-em-coleta-seletiva/>. Acesso em: 20 mai. 2020.

BACICH, L.; MORAN, J. Metodologias ativas para uma educação inovadora: uma abordagem teórico-prática. Porto Alegre: Penso, 2018.

BRASIL. Secretaria de Educação Fundamental. Parâmetros curriculares nacionais: meio ambiente, saúde. Brasília, 1997. [Link]

BRASIL. Ministério da Educação. PCN+ ensino médio: orientações educacionais complementares aos parâmetros curriculares nacionais ciências da natureza, matemática e suas tecnologias. Brasília, 2002. [Link]

BRASIL, D. R.; RESENDE, B. F. F.; ZIM, L. F. O agravamento da poluição química das águas subterrâneas. Direito Ambiental e Sociedade, v. 6, n. 1, p. 101-128, 2016. [Link]

BRASIL. Banco Nacional Comum Curricular. Brasília: Ministério da Educação, 2018. Disponível em: <http://basenacionalcomum.mec.gov.br/images/BNCC_EI_EF_110518_versaofinal_site.pdf>. Acesso em: 13 abr. 2020.

BRITO, R. O.; SIVERES, L.; CUNHA, C. O uso de indicadores para avaliação qualitativa de projetos educativos socioambientais: a gestão participativa no ambiente escolar. Ensaio: Aval. Pol. Educ., v. 27, n. 104, p. 610-630, 2019. [Link] 
BUFFOLO, A. C. C.; RODRIGUES, M. A. Agrotóxicos: uma proposta socioambiental reflexiva no Ensino de Química sob a perspectiva CTS. Investigações em Ensino de Ciências, v. 20, n. 1, p. 1-14, 2015. [Link]

CARVALHO, A. M. P.; GIL-PÉREZ, D. Formação de professores de ciências: tendências e

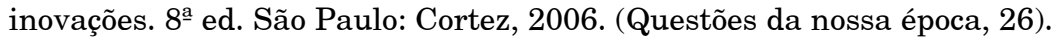

CARVALHO, F. R.; WATANABE, G. A construção do conhecimento científico escolar: hipóteses de transição identificadas a partir das ideias dos (as) alunos (as). Educação em Revista, v. 35, 2019. [Link]

CHIARO, S.; AQUINO, K. A. S. Argumentação na sala de aula e seu potencial metacognitvo como caminho para um enfoque CTS no Ensino de Química: uma proposta analítica. Educação \& Pesquisa (São Paulo), v. 43, n. 2, p. 411-426, 2017. [Link]

COSTA, H. H. C.; LOPES, A. C. A contextualização do conhecimento no Ensino Médio: tentativas de controle do outro. Educação \& Sociedade, v. 39, n. 143, p. 301-320, 2018. [Link]

COSTA, D.; PONTAROLO, E. Aspectos da educação ambiental crítica no ensino fundamental por meio de atividades de modelagem matemática. Revista Brasileira de Estudos Pedagógicos, v. 100 , n. 254 , p. $149-168,2019$. [Link]

CRESWELL, J. W. Projeto de pesquisa: métodos qualitativo, quantitativo e misto. $2^{\mathrm{a}}$ ed. Porto Alegre: Artmed, 2007.

DINIZ, F. E.; SILVA, C. D. D.; SILVA, O. G.; SANTOS, D. B. O Ensino de Química integrados a temas ambientais: um relato de experiências com escolares do Ensino Médio. Research, Society and Development, v. 10, n. 8, p. 1-9, 2021. [Link]

DOMICIANO, T. D.; LORENZETTI, L. A educação ciência, tecnologia e sociedade no curso de Licenciatura em Ciências da UFPR Litoral. Ensaio, v. 22, p. 1-25, 2020. [Link]

FIDELIS, J. P. S.; GIBIN, G. B. Contextualização como estratégia didática em vídeo-aulas de química. Revista Virtual de Química, v. 8, n. 3, p. 716-722, 2016. [Link]

FREIRE, P. Pedagogia do Oprimido. 60aㅡ ed. Rio de Janeiro: Paz e Terra, 2016.

FREITAS, N. M. S.; MARQUES, C. A. Sustentabilidade e CTS: o necessário diálogo na/para a Educação em Ciência em tempos de crise ambiental. Educar em Revista, v. 35, n. 77, p. 265282, 2019. [Link]

GALIAZZI, M. C.; SOUSA, R. S. A dialética na categorização da análise textual discursiva: o movimento recursivo entre palavra e conceito. Pesquisa Qualitativa, v. 7, n. 13, p. 01-22, 2019. [Link]

GRASSI, M. T. As águas do planeta Terra. Química Nova na Escola. Ed. Especial, p. 31-40, 2001. [Link]

HERNÁNDEZ, E. S.; MARTÍNEZ, X. U. La cuestión socioambiental: estúdio descriptivo sobre la presencia del tema em los Seminários Latinoamericanos de Escuelas de Trabajo Social. Katál, v. 22, n. 2, p. 413-425, 2019. [Link]

LATINI, R. M.; SOUSA, A. C. Ensino de Química e ambiente: as articulações presentes na revista Química Nova na Escola (QNEsc). Investigações em Ensino de Ciências, v. 16, n. 1, p.143-159, 2011. [Link]

LUDKE, M.; ANDRÉ, M. E. D. A. Pesquisa em educação: abordagens qualitativas. $2^{a}$ ed. Rio de Janeiro: EPU, 2014. 
COSTA-BEBER, L. B.; RITTER, J.; MALDANER, O. A. O mundo da vida e o mundo da escola: aproximações com o princípio da contextualização na organização curricular da educação básica. Química Nova na Escola, v. 37, noํespecial, p. 11-18, 2015. [Link]

MORAES, R. Uma tempestade de luz: a compreensão possibilitada pela análise textual discursiva. Ciência \& Educação, v. 9, n. 2, p. 191-2011, 2003. [Link]

NEVES, V. J.; LIMA, M. T.; MERCANTI, L. B.; COSTA, D. J. A. Metodologias ativas: inovações educacionais no ensino superior. Campinas: Pontes Editores, 2019.

OLIVEIRA, E. J. A.; MOLICA, R. J. R. A poluição das águas e as cianobactérias. Recife: IFPE, 2017.

POZO, J. I.; CRESPO, M. Á. G. A aprendizagem e o ensino de ciências: do conhecimento cotidiano ao conhecimento científico. $5^{\mathrm{a}}$ ed. Porto Alegre: Artmed, 2009.

SANTOS, W. L. P.; MORTIMER, E. F. Uma análise de pressupostos teóricos da abordagem C-T-S (Ciência- Tecnologia-Sociedade) no contexto da educação brasileira. Ensaio: Pesquisa em Educação em Ciências, v. 2, n. 2, p. 110-132, 2002. [Link]

SANTOS, R. V. Abordagens do processo de ensino e aprendizagem. Integração, ano XI, n. 40, p. 19-31, 2005.

SANTOS, W. L. P. Contextualização no Ensino de Ciências por meio de temas CTS em uma perspectiva crítica. Ciência \& Ensino, v. 1, no esp., p. 1-12, 2007. [Link]

SHULMAN, L. S. Those who understand: knowledge growth in teaching. Educational Researcher, v. 15, n. 2, p. 4-14, 1986.

SILVA, P. B.; BEZERRA, V. S.; GREGO, A.; SOUZA, L. H. A. A Pedagogia de Projetos no Ensino de Química (o caminho das águas na região metropolitana do Recife): dos mananciais ao reaproveitamento dos esgotos. Química Nova na Escola, n. 29, p. 14-19, 2008. [Link]

WATANABE, G.; RODRÍGUEZ-MARÍN, F. Aspectos da complexidade nas questões socioambientais: as abordagens no Brasil e na Espanha. Ciência \& Educação, n. 3, p. 543-562, 2018. [Link]

XAVIER, A. N. O.; SOLEDADE, J. S. A "leitura" do audiovisual e a formação do cidadão crítico. In: Encontro de Educomunicação da Região Sul - Educomunicação e Direitos Humanos, 2, 2013, Ijuí. Anais... Ijuí: Educom Sul, 2013. [Link]

ZABALA, A. Como aprender e ensinar competências. Porto Alegre: Artmed, 2010.

ZANIRATO, S. H.; ROTONDARO, T. Consumo, um dos dilemas da sustentabilidade. Estudos Avançados, v. 30, n. 88, p. 78-92, 2016. [Link]

ZANOTTO, R. L.; SILVERIA, R. M. C. F.; SAUER, E. Ensino de conceitos químicos em um enfoque CTS a partir de saberes populares. Ciência \& Educação, v. 22, n. 3, p. 727-740, 2016. [Link] 